\title{
Association of Gene Polymorphisms and Serum Levels of IL-18 with the Susceptibility to Infection with Hepatitis B Virus
}

Farah Thamer Hasan and Hassan Mohammad Naif*

Molecular Virology Laboratory, Department of Molecular and Medical Biotechnology, College of Biotechnology, Al-Nahrain University, Aljadriyah, Baghdad, Iraq

\begin{abstract}
Background: IL-18 gene polymorphisms is shown to be involved in various diseases. This study examines the influence of IL-18 gene polymorphism on the natural course of Hepatitis B Virus (HBV) infection together with the impact of serum levels in Iraqi population for the first time.

Methods: A total of 55 patients and similar numbers of healthy controls were recruited in this study. Gene polymorphisms at positions $-607 \mathrm{C} / \mathrm{A}$ and $-137 \mathrm{G} / \mathrm{C}$ of IL-18 were examined using the allele-specific polymerase chain reaction (PCR). Serum levels of IL-18 were determined by an ELISA kit.

Results: Three genotypes of IL-18-607C/A (rs1946518) were observed and distributed variably in both patients and controls: CC, CA, and AA with frequencies $41(82 \%), 3(6 \%)$, and $6(12 \%)$, in patients and in $44(88 \%), 5(10 \%)$, and $1(2 \%)$ in the controls, respectively. The homozygous -607AA mutant genotype, $A$ and $C$ allele frequencies were significantly higher $(p=0.043)$ in patients than the healthy control group (A: $15 \%$ and $7 \%, p=0.04$ and $\mathrm{C}: 85 \%$ and $93 \%, p=0.04$, respectively) ( $\mathrm{OR}=2.3445,95 \% \mathrm{Cl}=0.9121-6.0269)$. The effect of treatment against HBV on genotype and allele frequencies compared with untreated patients revealed that $C C$ and $A A$ genotypes were significantly higher $(p=0.04)$ in treated than untreated patients mirrored results obtained in patients and controls. Three genotypes of IL-18-137G/C (rs187238) were observed in both patients and healthy controls: GG, GC, and CC that appeared in $30(60 \%), 18(36 \%)$, and $2(4 \%)$ of HBV infected patients and in $32(64 \%), 16(32 \%)$, and $2(4 \%)$ of the control group, respectively. No significant genotype or alleles $(\mathrm{G}$ and $\mathrm{C})$ frequencies observed between patients and controls $(\mathrm{OR}=0.863,95 \% \mathrm{Cl}=0.4485-1.7516)$. Serum levels of IL-18 was found to be significantly higher in HBV-infected patients compared to the control group. IL-18 levels decreased significantly by various genotypes of both SNPs and this was consistently associated with the mutant genotypes of -137 SNP.
\end{abstract}

Conclusion: IL-18-607AA mutant genotype and $C$ and A alleles were significantly associated with a high risk to HBV infection in Iraqi population, however, the -137 genotypes had no clear impact on the disease and its role as a protective factor needs further investigation. In contrast, the downregulation of the circulating levels of IL-18 in patients was associated with the -137 and -607 mutant genotypes.

Keywords: Hepatitis; HBV; IL-18; polymorphism

\section{Introduction}

Hepatitis B Virus (HBV) infection affecting more than two billion people are living with this virus and about 400 million remain infected chronically and become carriers. In addition, every year there are over ten millions new acute cases of HBV [1]. Out of those chronic cases, either they live as asymptomatic carriers or die due to cirrhosis or hepatocellular carcinoma (HCC) [2,3]. Such highly variable outcomes may be generally attributed to viral or environmental factors, along with immunological status and genetic history [4].

Cytokines and other regulatory molecules play an important role in the immunopathogenesis of HBV infection, therefore, might affect susceptibility to HBV and/or the natural course of the infection [5]. The gene loci for cytokines are defined, and polymorphisms of cytokine genes are suggested to influence the outcome of HBV infection [6]. Therefore, many recent studies have focused on the effect of gene polymorphisms of cytokines on disease outcome such as prediction of infection risk, disease progression, chronicity and response to vaccination and treatment as well as vertical transmission [7-10].

Interleukin-18 is a pro-inflammatory cytokine belonging to the IL-1 family and can be involved in both innate and adaptive immunity. It promotes Th1 immune responses and can induce IFN- $\gamma$, IL-18 is expressed at sites of chronic inflammation, in autoimmune diseases, in a variety of cancers including hepatocellular carcinoma, and in the pathogenesis of numerous infectious diseases inclusing HBV infection [4]. It is reported to inhibit hepatitis B virus (HBV) replication in the liver of HBV transgenic mice; however, the molecular mechanism of its antiviral effect has not been fully understood. It was demonstrated that IL-18 directly inhibited HBV replication in HepG2.2.15 cells via down regulating the activities of $\mathrm{HBV}$ core and $\mathrm{X}$ gene promoters. This inhibitory effect by IL-18 could be rescued by the administration of BAY11-7082, an inhibitor of transcription factor NF- $k B$. Furthermore, it was confirmed that expression of IL-18/IL-18R were remarkably up regulated in hepatocellular carcinoma (HCC) liver cancer tissue specimens, suggesting that IL-18 is involved in HCC metastasis in addition to its suppressive effect on HBV replication [11,12].

*Corresponding author: Hassan M Naif, Molecular Virology Laboratory, Department of Molecular and Medical Biotechnology, College of Biotechnology, Al-Nahrain University, Aljadriyah, Baghdad, Iraq, Tel: +9647802731101; E-mail: drnaifhassan@gmail.com

Received: October 15, 2017; Accepted: October 23, 2017; Published: November 10, 2017

Citation: Hasan FT, Naif HM (2017) Association of Gene Polymorphisms and Serum Levels of IL-18 with the Susceptibility to Infection with Hepatitis B Virus. J Infect Dis Med 2: 117. doi: 10.4172/2576-1420.1000117

Copyright: @ 2017 Hasan FT, et al. This is an open-access article distributed unde the terms of the Creative Commons Attribution License, which permits unrestricted use, distribution, and reproduction in any medium, provided the original author and source are credited. 
The human IL-18 gene is located on chromosome 11q22.2-22.3 and consists of six exons and five introns. So far, three single nucleotide polymorphisms (SNPs) in the promoter region of the IL-18 gene have been elucidated, namely $-656 \mathrm{G} / \mathrm{T}$ (rs1946518), -607C/A (rs1946519), and $-137 \mathrm{G} / \mathrm{C}(\mathrm{rs} 187238)$ [13].

This study is designed to the possible role of IL-18 $-607 \mathrm{C} / \mathrm{A}$ and $-137 \mathrm{G} / \mathrm{C}$ polymorphisms on the susceptibility to $\mathrm{HBV}$ infection and their impact on serum levels of IL-18 in patients and healthy controls from Iraq.

\section{Materials and Methods}

\section{Characteristics of study population}

In this study, fifty patients infected with HBV presented to the Department of Gastroenterology, Medical City Hospital in Baghdad. Family unrelated apparently 50 healthy individuals with no history of previous liver disease, normal liver function tests and negative HBV and HCV serology from the same Hospital were selected to represent the control group. The mean ages of patients and control were $36 \pm 14$ and $35 \pm 16$ respectively. Patients with HCV or other viral infections or any other liver diseases were excluded from the study. All procedures were conducted in accordance with the ethical standards of the Human Ethics Committee of the Ministry of Health. A written informed consent was obtained from all subjects after receiving approval of the experimental protocol the ethics committee and with the Helsinki Declaration of 1975. For collecting a demographical data about the individuals a case history form was used to include age, sex, occupation, smoking, drinking, residence, and other diseases.

\section{Detection of HBV antigen}

Hepatitis B surface antigen (HBsAg) was tested using commercially a ready-made kit (gSYNCTM DNA Mini Kit, Whole Blood Protocol, Geneaid, Korea) according to the manufacturer's instructions.

\section{Determination of IL-18 genotypes}

IL-18-137G/C and -607C/A SNPs were examined using the allele specific polymerase chine reaction (AS-PCR) and three primers mix (Table 1). The PCR performed in two tubes and each one contains a control primer pair (forward and reverse) and the specific primer set for the target allele for each SNP. The final total volume of each reaction was $20 \mu \mathrm{l}$ when each tube has $10 \mu \mathrm{l}$ master mix and $1 \mu \mathrm{l}$ forward primer, $1 \mu \mathrm{l}$ specific primer, $2 \mu \mathrm{l}$ reverse primer, $4 \mu \mathrm{l}$ nuclease free water, and 2 $\mu \mathrm{l}$ DNA. The PCR cycling for $-137 \mathrm{G} / \mathrm{C}$ was one cycle of $95^{\circ} \mathrm{C}$ for $5 \mathrm{~min}$; followed by $35 \mathrm{cycles}$ of $94^{\circ} \mathrm{C}$ for $30 \mathrm{sec}, 57^{\circ} \mathrm{C}$ for $30 \mathrm{~min}$ and $72^{\circ} \mathrm{C}$ for 30 sec; 1 cycle of $72^{\circ} \mathrm{C}$ for $5 \mathrm{~min}$. The same PCR cycling for -607 except that the annealing temperature was $54^{\circ} \mathrm{C}$ for $1 \mathrm{~min}$. The PCR was performed in a Thermocycler from (Techne- tc-5000, Applied Biosystems, and USA). The PCR products were visualized on a $2 \%$ agarose gel and length/size was estimated in comparison with a $100 \mathrm{bp}$ DNA ladder (Kappa Biosystems, USA). The size of the products of PCR were $196 \mathrm{bp}$ represents the amplification of IL-18-607C/A (Figure 1A) and $261 \mathrm{bp}$ DNA bands represent the amplification of IL-18-137G/C (Figure 1B). The amplicons of the internal controls used in both reactions were 446 $\mathrm{bp}$, and $301 \mathrm{bp}$, respectively.

\section{Serum levels of IL-18}

A commercially available kit for human IL-18 (Human, China) was used to measure serum levels of IL-18 in patients and healthy controls according to the kits manufacturers' instruction. The Micro ELISA system reader (Thermo, Germany) were used to read the absorbance and a standard curve readily processes from this cytokine concentrations of unknown samples can be derived directly and expressed as $\mathrm{ng} / \mathrm{l}$.

\begin{tabular}{|c|c|c|}
\hline Gene & Primers $5^{\prime} \rightarrow 3^{\prime}$ & Amplicon (bp) \\
\hline$I L-18-137$ & $\begin{array}{c}\text { Internal control Primers } \\
\text { Reverse: AGGAGGGCAAAATGCACTGG } \\
\text { Forward: CCAATAGGACTGATTATTCCGCA } \\
\text { Specific mutant primers } \\
\text { CCCCAACTTTTACGGAAGAAAAC } \\
\text { CCCCAACTTTTACGGAAGAAAAG }\end{array}$ & $\begin{array}{l}446 \\
261\end{array}$ \\
\hline IL-18 -607 & $\begin{array}{c}\text { Internal control Primers } \\
\text { Reverse: TAACCTCATTCAGGACTTCC } \\
\text { Forward: CTTTGCTATCATTCCACGAA } \\
\text { Specific mutant primers } \\
\text { GTTGCAGAAAGTGTAAAAATTATTAC } \\
\text { GTTGCAGAAAGTGTAAAAATTATTAA }\end{array}$ & $\begin{array}{l}301 \\
196\end{array}$ \\
\hline
\end{tabular}

Table 1: Primer pair sets and their sequences and corresponding genes together with amplicon size.
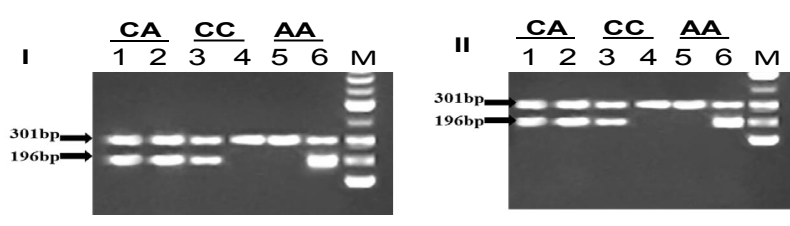

Figure 1A: Genotyping of IL-18(-607C/A) alleles' distribution in HBV infected patients (I) and in healthy control individuals (II) by using allele-specific (AS) PCR. Experimental conditions and internal control are similar to those described in Figure 3. The 196 bp represents the amplification of IL-18-607C/A, while the 301 bp representing the internal control gene. Lanes order: lanes 1-2, CA; lanes 3-4, CC; lanes 5-6, AA; lane M; DNA marker.

\section{Statistical Analysis}

Data were expressed as a mean \pm standard deviation. The Statistical Package for the Social Sciences (SPSS, version 14) was used for statistical analysis. Risk association between the genotype and HBV susceptibility was determined by the calculation of adjusted odd ratio (OR) and $95 \%$ confidence intervals $(95 \% \mathrm{CI})$ using multivariate logistic regression. For this analysis, subjects who were homozygous for the wild type allele were considered as reference, and polymorphisms as dependent variables and the demographic and clinical features such as age, gender, family history, education status, residency and smoking are considered as co-variables in the model. The Statistical Analysis System- SAS 
Citation: Hasan FT, Naif HM (2017) Association of Gene Polymorphisms and Serum Levels of IL-18 with the Susceptibility to Infection with Hepatitis B Virus. J Infect Dis Med 2: 117. doi: 10.4172/2576-1420.1000117

Page 3 of 7

available kits of enzyme-linked immunosorbent assay (ELISA; SIEMENS, Enzygnost, USA). All patients were positive for HBsAg and negative for HCV antibodies. Alkaline phosphatase, Aspartate aminotransferase and Alanine aminotransferase were all measured according to manufacturer's instructions for respective kits (Human, Germany).

\section{DNA extraction}

Five milliliters $(\mathrm{ml})$ of venous blood was collected from each participant. Two $\mathrm{ml}$ of which were kept in EDTA tubes and the other 3 $\mathrm{ml}$ were placed in plane tubes. The latter was undergone centrifugation where the serum was obtained and preserved at $-20^{\circ} \mathrm{C}$ until used in ELISA. DNA was extracted from whole blood-EDTA samples using

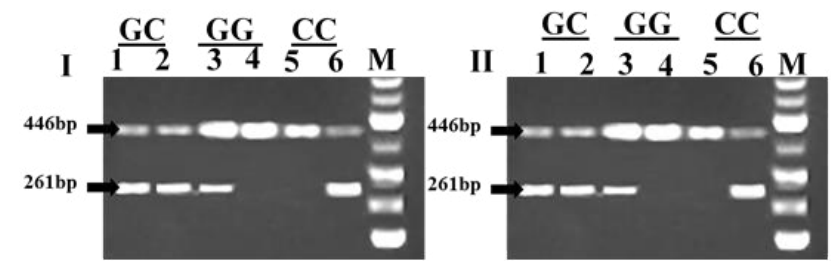

Figure 1B: Genotyping of IL-18 (-137G/C) alleles' distribution in HBV infected patients (I) and in healthy control individuals (II) by using allele-specific (AS) PCR. Experimental conditions and internal control are similar to those described in Figure 3. The 261 bp represents the amplification of IL-18-137G/C, while the $446 \mathrm{bp}$ represents the amplification of the internal control from the same gene of IL-18. Lanes order: lanes 1-2, GC; lanes 3-4, GG; lanes 5-6, CC, lane M; DNA marker
(2012) program was used to demonstrate the effect of difference factors in study parameters such as chi-square and/or Fisher exact tests and the $P$ value.

\section{Results}

\section{Clinical and demographical characteristic of study population}

A total of 100 subjects were used in this study for analysis of the relationship between gene polymorphism of cytokines, particularly IL-10 and IL-18, and susceptibility to HBV infection. The subjects of this case control study comprised from 32 males and 18 females of HBV infected patients and 27 males and 23 females of the healthy controls at an average age of $36 \pm 14$ of infected patients and $35 \pm 16$ years of uninfected controls (Tables 1-3). Individuals were all tested for HBV by using antigen test (HBsAg) by ELISA for confirmation of the positives from the negatives. Risk factors such as the smoking status of both groups were relatively equal in numbers and the majority had no diabetes mellitus or blood pressure. The concentrations of aspartate aminotransferase (AST), alanine aminotransferase (ALT) and alkaline phosphatase (ALP) were within the normal range for both the patients and healthy controls.

\section{Association between IL-18 -607C/A SNP and Risk to HBV- infection}

Analysis of IL-18-607 C/A polymorphism, three genotypes were observed in both patients and controls: CC, CA, and AA at variable frequencies. In $\mathrm{HBV}$ infected patients, the genotype distributions were $41(82 \%), 3(6 \%)$, and $6(12 \%)$, respectively; while were $44(88 \%), 5$

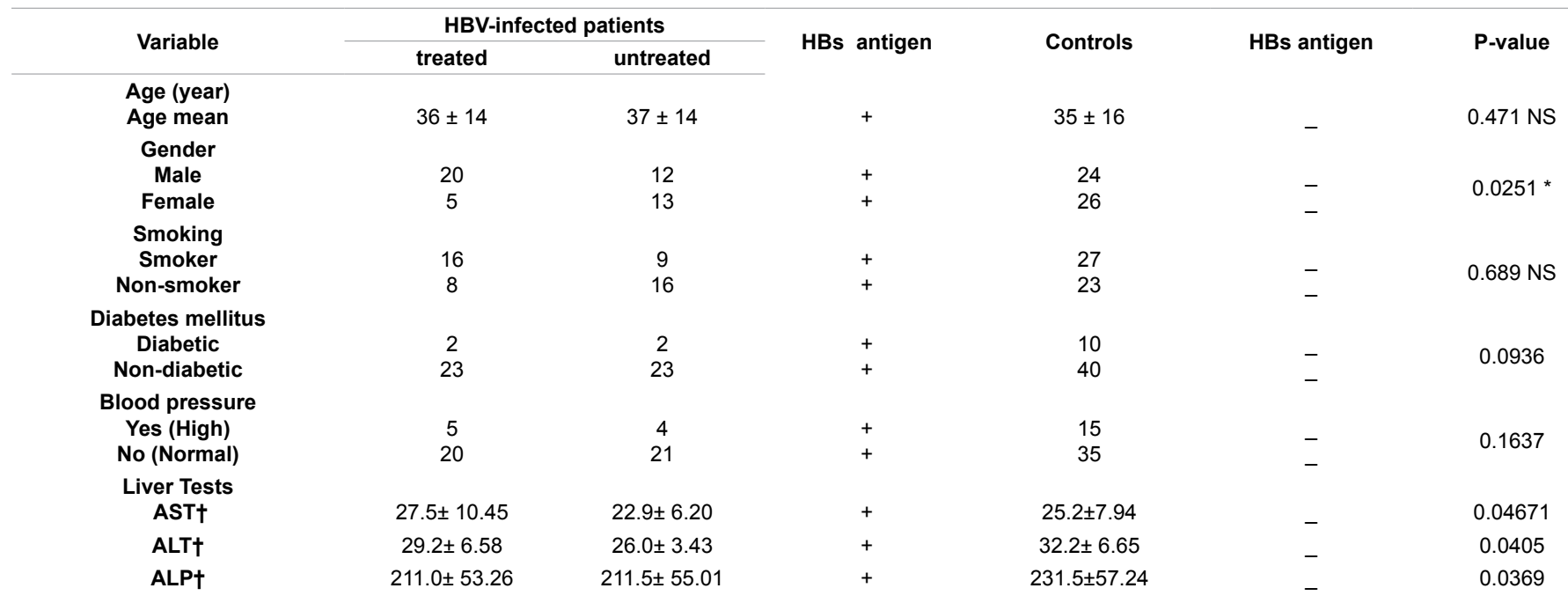

Abbreviations: AST, aspartate transaminase at a normal range up to 28 for male and 25 for female; ALT, alanine aminotransferase at a normal range up to 42 for male and 32 for female; ALP, alkaline phosphatase at a normal range up to 61-232 for male and 49-232 for female; †, LSD mean values for AST (3.285*), ALT (4.017*), and ALP $\left(37.582^{*}\right)$. HBV antigen examined by ELISA.

Table 2 Clinical data and risk factors of study population including patients with hepatitis B virus (HBV) infection and uninfected controls.

\begin{tabular}{|c|c|c|c|c|}
\hline Genotype & Cases(N=50) & Controls(N=50) & P-value \\
\hline CC & $41(82 \%)$ & $44(88 \%)$ & 0.0823 & $0.308(0.89-1.62)$ \\
\hline CA & $3(6 \%)$ & $5(10 \%)$ & 0.0983 \\
\hline AA & $6(12 \%)$ & $1(2 \%)$ & $0.0431^{*}$ \\
\hline & & Allele frequencies & \\
\hline C & 85 & 93 & $0.618(0.87-1.61)$ \\
\hline A & 15 & 07 & $0.0473^{*}$ \\
\hline${ }^{*} P<0.05$ significant; $P>0.05:$ non-significant & & \\
\hline
\end{tabular}

Table 3: The genotype and allele frequencies of IL-18 polymorphism (-607C/A, rs 1946518) in HBV infected patients (cases) and healthy controls. 


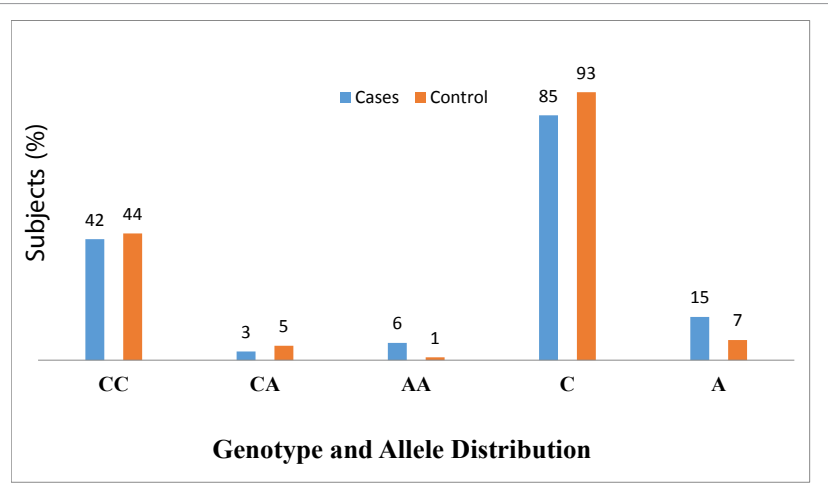

Figure 2: Genotypes and alleles frequencies of IL-18 (-607 C/A) polymorphism in HBV infected patients and healthy controls

(10\%), and $1(2 \%)$ in the controls, respectively. The homozygous AA mutant was the only significant $(\mathrm{P}=0.043)$ result between the genotype analysis between patients and controls (Figure 2). Analysis of allele frequencies of IL-18 -607C/A SNP revealed significant differences in frequency of $\mathrm{C}$ allele between HBV patient and controls (85\% and $93 \%$, $\mathrm{P}=0.04$, respectively $)(\mathrm{OR}=2.3445,95 \% \mathrm{CI}=0.9121-6.0269)$. Similarly, the frequency of A allele was also significantly different between the two groups ( $15 \%$ and $7 \%, \mathrm{P}=0.04$, respectively).

The effect of treatment against HBV on genotype and allele frequencies compared with untreated patients revealed that CC and AA genotypes were significantly higher (0.04) in treated than untreated patients mirrored results obtained in patients and controls. In the treated patients, the three genotypes (CC, CA, AA) appeared in $19(72 \%), 2(8 \%)$, and $4(16 \%)$, respectively. In untreated cases, there were $22(88 \%), 1(4 \%)$, and $2(8 \%)$, respectively. The homozygous wild type $\mathrm{CC}(\mathrm{P}=0.042)$ and the mutant AA $(\mathrm{P}=0.04)$ showed significant differences between the patients and controls, but not the heterozygous mutant $\mathrm{CA}(\mathrm{P}=0.09)$.

In treated versus untreated patients, the allele frequencies of this SNP (IL-18-607C/A) revealed significant differences in frequency of $\mathrm{C}$ allele between $\mathrm{HBV}$ treated and newly diagnosed untreated patients ( $80 \%$ and $90 \%, \mathrm{P}=0.04$, respectively) ( $\mathrm{OR}=0.4444,95 \% \mathrm{CI}=0.9164$ 1.0058) (Table 4). Similar results were obtained for the frequency in allele A between the two groups ( $20 \%$ and $10 \%, \mathrm{P}=0.04$; respectively).

\section{Association between $-317 \mathrm{G} / \mathrm{C}$ SNP and risk to $\mathrm{HBV}$ infection}

The SNP of IL-18 (-317G/C, rs187238) in both patients and healthy controls had three genotypes: GG, GC, and CC. In that genotype order, they appeared in HBV infected patients in $30(60 \%), 18$ (36\%), and 2 (4\%), respectively; whereas in the control group they were $32(64 \%)$, $16(32 \%)$, and $2(4 \%)$, respectively. There was no significant differences between the genotype distribution for all the three genotypes and results were not significant ( $\mathrm{p}=0.0983,0.0983$, and 1.00 , respectively) (Table 5).

Analysis of allele frequencies of this SNP (IL-18-137G/C) revealed no significant allele frequency of $\mathrm{G}$ allele between $\mathrm{HBV}$ patient and controls $(78 \%$ and $80 \%, \mathrm{P}=0.863)$, respectively. Similar results were obtained for the frequency of $\mathrm{C}$ allele between the two groups $(22 \%$ and $20 \%, \mathrm{OR}=0.863,95 \% \mathrm{CI}=0.4485-1.7516$ ), respectively (Tables 5 and 6 and Figure 3).

The genotypes GG, GC, CC of treated HBV-infected patients appeared in $13(52.00 \%), 11(44.00 \%)$, and $1(4.00 \%)$, respectively; compared to $17(68.00 \%), 7(28.00 \%)$, and $1(4.00 \%)$ in the newly

\begin{tabular}{|c|c|c|c|c|}
\hline Genotype & $\begin{array}{c}\text { Treated cases } \\
(\mathbf{N}=\mathbf{2 5})\end{array}$ & $\begin{array}{c}\text { Untreated cases } \\
\mathbf{( N = 2 5 )}\end{array}$ & P-value & OR (95\%Cl) \\
\hline CC & $19(76.00 \%)$ & $22(88.00 \%)$ & $0.0425^{*}$ & $0.702(0.90-1.62)$ \\
\hline CA & $2(8.00 \%)$ & $1(4.00 \%)$ & $0.098 N S$ & $0.241(0.87-1.62)$ \\
\hline AA & $4(16.00 \%)$ & $2(8.00 \%)$ & $0.0491^{*}$ & $0.652(0.88-1.61)$ \\
\hline \multicolumn{5}{|c|}{ Allele frequencies } \\
\hline C & 80 & 90 & $0.041^{*}$ & $0.444(0.91-1.00)$ \\
\hline A & 20 & 10 & $0.041^{*}$ & -- \\
\hline (P<0.05), NS: Non-Significant & \\
\hline
\end{tabular}

Table 4: The genotype and allele frequencies of IL-18 polymorphism (-607C/A rs1946518) in HBV treated and untreated newly diagnosed cases.

\begin{tabular}{|c|c|c|c|c|}
\hline Genotype & $\begin{array}{c}\text { Cases } \\
\mathbf{( N = 5 0 )}\end{array}$ & $\begin{array}{c}\text { Control } \\
\mathbf{( N = 5 0 )}\end{array}$ & P-value & OR (95\%Cl) \\
\hline GG & $30(60 \%)$ & $32(64 \%)$ & 0.0983 & $0.241(0.87-1.62)$ \\
\hline GC & $18(36 \%)$ & $16(32 \%)$ & 0.0983 & $0.241(0.87-1.62)$ \\
\hline CC & $2(4 \%)$ & $2(4 \%)$ & 1.00 & $0.00(0.86-1.60)$ \\
\hline \multicolumn{5}{|c|}{ Allele frequencies } \\
\hline G & 78 & 80 & 0.863 & $0.863(0.44-1.75)$ \\
\hline C & 22 & 20 & 0.863 & --- \\
\hline
\end{tabular}

P>0.05: non-significant

Table 5: The genotype and allele frequencies of IL-18-137 polymorphism (-317G/ $\mathrm{C}, \mathrm{rs} 187238)$ in HBV infected cases and healthy controls.

\begin{tabular}{|c|c|c|c|c|}
\hline Genotype & $\begin{array}{c}\text { Treated } \\
\text { cases (N=25) }\end{array}$ & $\begin{array}{c}\text { Untreated } \\
\text { cases (N=25) }\end{array}$ & P-value & OR (95\%Cl) \\
\hline GG & $13(52.00 \%)$ & $17(68.00 \%)$ & $0.0104^{* *}$ & $1.077(0.91-1.63)$ \\
\hline GC & $11(44.00 \%)$ & $7(28.00 \%)$ & $0.0104^{* *}$ & $1.077(0.91-1.63)$ \\
\hline CC & $1(4.00 \%)$ & $1(4.00 \%)$ & $1.00 \mathrm{NS}$ & $0.00(0.88-1.61)$ \\
\hline \multicolumn{5}{|c|}{ Allele frequencies } \\
\hline G & 74 & 82 & $0.0473^{*}$ & $0.6248(0.31-1.23)$ \\
\hline C & 26 & 18 & $0.0473^{*}$ & --- \\
\hline (P<0.05), ${ }^{* *}(\mathbf{P}<0.01)$, NS: Non-Significant \\
\hline
\end{tabular}

Table 6: Distribution of IL-18 polymorphism (-137, rs187238) genotype and allele frequencies in HBV infected treated and untreated newly diagnosed cases.

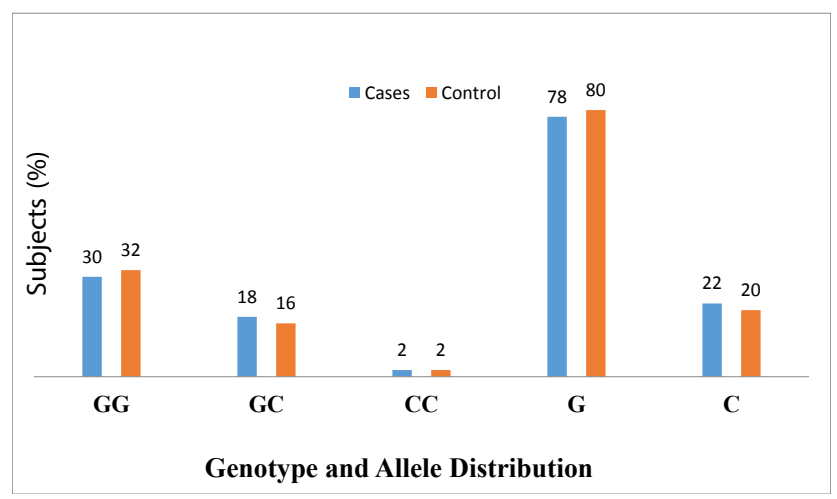

Figure 3: Genotypes and alleles frequencies of IL-18 (-137 G/C) polymorphism in HBV infected patients and healthy controls.

diagnosed untreated patients, respectively (Table 6). When the genotypes of treated and newly diagnosed cases were compared, both the homozygous GG and the heterozygous GC genotypes, but not the case with the homozygous $\mathrm{CC}$ mutant genotype $(\mathrm{P}=1.00)$, showed significant correlations ( $\mathrm{P}=0.01$ for both genotypes). The allele frequency differences between treated vs untreated patients was significant for the $\mathrm{G}(74 \%$ and $82 \%, \mathrm{P}=0.04)$ and $\mathrm{C}$ alleles $(26 \%$ and $18 \%)$, respectively $(\mathrm{OR}=0.6248,95 \% \mathrm{CI}=0.3171-1.2310)$. 


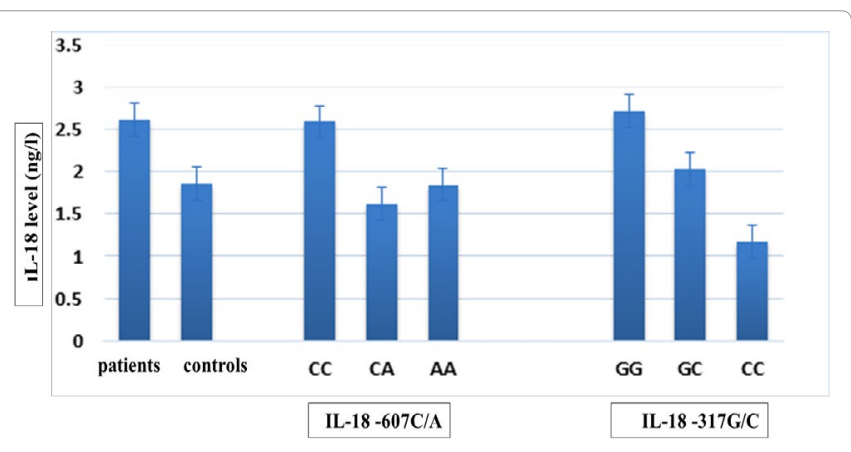

Figure 4: IL-18 levels in sera from HBV patients and healthy controls measured by an ELISA kit (human interleukin 18 ELISA Kit).

Circulating levels of IL-18 in HBV infected patients and healthy controls and its correlation with polymorphism genotypes

The levels of IL-18 in the sera obtained from HBV patients were significantly higher $(2.61 \pm 2.75 \mathrm{ng} / \mathrm{l})$ than control group $(1.26 \pm 1.22$ ng/l) $(t=0.894, P=0.00275)$ (Figure 4).

The correlation between IL-18 levels and the three genotypes (CC, $\mathrm{CA}$ and AA) of IL-18(-607C/A) polymorphism in sera from HBV infected patients revealed that patients who had the wild type CC genotype ended up with the highest levels of IL-18 $(2.59 \pm 1.88 \mathrm{ng} / \mathrm{l})$, followed by the homozygous mutant AA genotype $(1.85 \pm 1.20 \mathrm{ng} / \mathrm{l})$ and then by the heterozygous mutant CA genotype as being the lowest $(1.602 \pm 1.25 \mathrm{ng} / \mathrm{l})$. These differences were significant for the three genotypes $(\mathrm{F}=0.652, P=0.0376)$.

The association between the levels of circulating IL-18 with the three genotypes GG, GC and CC of IL-18-317G/C polymorphism in sera from HBV infected patients revealed that patients with the wild type GG genotype had the highest levels of IL-18 $(2.71 \pm 2.23 \mathrm{ng} / \mathrm{l})$, followed by the heterozygous mutant GC genotype $(2.03 \pm 1.89$ $\mathrm{ng} / \mathrm{l})$ and then by the homozygous mutant CC genotype as being the lowest $(1.18 \pm 1.04 \mathrm{ng} / \mathrm{l})$. The differences were significant for the three genotypes $(\mathrm{F}=0.652, P=0.0376)$. These indicate that the $-607 \mathrm{C} / \mathrm{A}$ and $-137 \mathrm{G} / \mathrm{C}$ polymorphisms in the $I L-18$ gene may play a pivotal role in the secretion of IL- 18 .

\section{Discussion}

This study is designed to investigate the possible association between the gene polymorphism and circulating serum levels of Th1 (IL-18) cytokine with susceptibility to HBV infection in Iraq population for the first time. The genotype frequencies of all variants were within the Hardy-Weinberg equilibrium (HWE) in either patients or the control group. The main goal of this project is to understand the genetic background of this common public health problem which may provide means to new strategies for defining biomarkers for seroconversion, risk factors association and prognosis as well as evaluation of treatment and vaccination response to $\mathrm{HBV}$ infection. In the present study, three genotypes of IL-18-607C/A (rs1946518) of were distributed variably in both patients and controls: CC, CA, and AA with frequencies $41(82 \%)$, $3(6 \%)$, and $6(12 \%)$, in patients while were $44(88 \%), 5(10 \%)$, and $1(2 \%)$ in the controls, respectively. The homozygous AA mutant genotype, A and $\mathrm{C}$ allele frequencies were significantly higher $(\mathrm{P}=0.043)$ in patients than the healthy control group (A: $15 \%$ and $7 \%, \mathrm{P}=0.04$ and $\mathrm{C}: 85 \%$ and $93 \%, \mathrm{P}=0.04$, respectively) $(\mathrm{OR}=2.3445,95 \% \mathrm{CI}=0.9121-6.0269)$. The effect of treatment against HBV on genotype and allele frequencies compared with untreated patients revealed that $\mathrm{CC}$ and AA genotypes were significantly higher $(\mathrm{P}=0.04)$ in treated than untreated patients mirrored results obtained in patients and controls. Three genotypes of IL-18-317G/C, rs187238 were observed in both patients and healthy controls: GG, GC, and CC that appeared in $30(60 \%), 18(36 \%)$, and 2 (4\%) of HBV infected patients and in 32 (64\%), 16 (32\%), and $2(4 \%)$ of the control group, respectively. No significant genotype and alleles ( $\mathrm{G}$ and $\mathrm{C}$ ) distribution between patients and controls. No significant differences of the allele frequencies of both $\mathrm{G}$ and $\mathrm{C}$ alleles between patients and controls $(\mathrm{OR}=0.863,95 \% \mathrm{CI}=0.4485-1.7516)$. Serum levels of IL-18 were found to be significantly higher in HBV-infected patients compared to the control group. IL-18 levels decreased significantly by different genotypes of both SNPs but were consistently associated with mutant genotypes of -137 SNP which may decrease Th1 immune response to fight HVB disease progression.

To date, there is currently a large amount of evidence on the association between cytokine gene polymorphisms and the natural course of chronic HBV infection, although with conflicting and inconclusive results. It has been shown that levels of immunity and response type can be affected by a single nucleotide polymorphism (SNP) in the promoter regions of cytokine genes which play a role in modulating gene expression and alteration the immune status of individuals and eventually increasing the susceptibility to hepatitis $\mathrm{B}$ and/or its clinical outcome. Thus, a number of reports have demonstrated statistically significant associations between cytokine gene polymrphisms and outcome of HBV infection [14-18]. In this study, the levels of IL-18 was much higher in patients compared to healthy controls which was reduced to lower levels at the same ratios by the influence of the heterozygous and homozygous mutants of IL18-137 SNP. On the other hand, the serum levels with the homozygous wild genotypes were significantly reduced by the influence of the heterozygous and homozygous mutant in an allele dependent manner for those who carry the IL-18-607 SNPs (rs 1946518). In conclusion, this study indicated that cytokine production was significantly influenced by the genotype frequency distribution. A possible positive relationship between serum IL-18 level and disease severity of HBV infection has been reported during a clinical study [19]. Another study conducted on a Chinese population, the IL-18-137 SNP with C allele was shown to be associated with protection against HBV infection [20]. The IL-18$137 \mathrm{G} / \mathrm{C}$ polymorphism, but not the $-607 \mathrm{~A} / \mathrm{C}$ polymorphism, showed a significant association with the risk of hepatocellular carcinoma [21]. Moreover, the IL-18-607 SNP with AA genotype was accompanied by inhibition of HBV DNA replication [20]. In addition, Migita et al. [22] in a study comprised of 204 chronically HBV-infected patients; suggested that IL-18 -607 and -137 had differential outcomes on HBV infection, where they found that these SNPs are significantly higher in inactive $\mathrm{HBV}$ carriers compared to those with chronic progressive liver disease. Moreover, Hirankarn et al. [23] found that A/A genotype of IL-18-607 SNP (rs1946518) can be used as a new genetic marker in Thai population for prediction of chronic hepatitis B development. Furthermore, it was fund that genotype AA and the allele A of the IL18-607 are closely associated with the resistance to chronic hepatitis $B$ [9]. In contrast, a larger scale meta-analysis revealed that both IL-18317 and -607 had no effects on HBV infection.

The mechanism of cytokines induce anti-HBV activities is either indirectly by influencing the type of the host response, or directly, through inhibition of viral replication [24]. In acute HBV infection, Th1 cytokines are released, to promote a dominant cellular cytotoxic T-lymphocyte (CTL) immune response $[25,26]$. On the other hand, Th2 response is dominated the chronic HBV infection [27]. The imbalance of Th1 and Th2 cytokine production patterns are a common phenomenon in chronic HBV infection [28,29]. Here, Th1 responses, as influenced by IL-18, were hindered by significant down regulation 
of serum levels particularly in -137 genotype carriers. The mechanism of how gene polymorphism influences cytokine production? Cytokine gene polymorphisms may change the structure and biological function of a certain cytokine coded by the defective gene leading to either increase or decrease of cytokine production. The inheritance of SNP may render people more susceptible or resistant to a certain diseases, therefore affecting cytokine secretion levels, and eventually may influence the outcome of HBV infection [30,31].

However, further studies are still needed to examine in more detail the effects of cytokine genetic polymorphisms and their clinical implications in HBV infected patients at various phases of natural disease course. It worth also include patients who respond or not to treatment and vaccine by recruiting a larger number of local patients. Examining mutations within and outside the coding regions may need a closer look. This future plan will be built on these findings to establish the link of genomic information of inflammatory and antiinflammatory regulators with the differential anti-HBV immunity and provide important insights into prognostic markers for disease progression and evaluation of treatment and vaccine responses of local population. Additional studies with larger samples and detailed clinical data are warranted in various local ethnic populations to avoid the limited study population included herein [32-36].

\section{Conclusion}

IL-18-607AA mutant genotype and $\mathrm{C}$ and $\mathrm{A}$ alleles were significantly associated with a high risk to HBV infection in Iraqi population, however, the -307 genotypes had no clear impact on the disease and its role as a protective factor needs further investigation. In contrast, the down regulation of the circulating levels of IL-18 in patients was associated with the -317 and -607 genotypes. The genotype of IL-18 SNPs may serve as a marker that can be used to identify a subgroup of patients who have a higher risk to chronic HBV infection.

\section{Acknowledgment}

The authors are grateful for the consultancy assistance provided by Dr. Safaa Abdl-Kareem Abdl- Razzaq, Director of Gastroenterology Department, medical City, and Ministry of Health.

\section{Conflict of Interest}

The authors declare no conflict of interest.

\section{References}

1. Carey WD (2009) The prevalence and natural history of hepatitis $B$ in the 21 st century. Clevel Clin J Med 76: S2-S5.

2. Fattovich G (2003) Natural history and prognosis of hepatitis B. Semin Liver Dis 23: $47-58$.

3. Lavanchy D (2004) Hepatitis B virus epidemiology, disease burden, treatment, and current and emerging prevention and control measures. J Viral Hepat 11: 97-107.

4. Nakanishi K (2002) Regulation of Th1 and Th2 immune responses by IL-18. Kekkaku 77: 87-93.

5. Grünhage F, Nattermann J (2010) Viral hepatitis: Human genes that limit infection. Best Pract Res Clin Gastroenterol 24: 709-723.

6. Thursz MR (1997) Host genetic factors influencing the outcome of hepatitis. J Viral Hepat 4: 215-220.

7. McNicholl JM, Downer MV, Udhayakumar V, Alper CA, Swerdlow DL (2000) Host-pathogen interactions in emerging and re-emerging infectious diseases: A genomic perspective of tuberculosis, malaria, human immunodeficiency virus infection, hepatitis b, and cholera. Annu Rev Public Health 21: 15-46.

8. Gong QM, Kong XF, Yang ZT, Xu J, Wang L, et al. (2009) Association study of IFNAR2 and IL10RB genes with the susceptibility and interferon response in HBV infection. J Viral Hepat 16: 674-680.
9. Li N, Gao YF, Zhang TC, Chen P, Li X, et al. (2012) Relationship between interleukin 18 polymorphisms and susceptibility to chronic hepatitis $B$ virus infection. World J Hepatol 4: 105-109.

10. Chatzidaki V, Choumerianou D, Dimitriou H, Kouroumalis E, Galanakis E, et al. (2012) Genetic variants associated with susceptibility to mother-to-child transmission of hepatitis B virus. Eur J Gastroenterol Hepatol 24: 1185-1190.

11. Zhang Y, Li Y, Ma Y, Liu S, She Y, et al. (2011) Dual effects of interleukin-18: inhibiting hepatitis B virus replication in HepG2. 2.15 cells and promoting hepatoma cells metastasis. Am J Physiol Gastrointest Liver Physiol 301: G565-G573

12. Biet $F$, Locht $C$, Kremer $L$ (2002) Immunoregulatory functions of interleukin 18 and its role in defense against bacterial pathogens. J Mol Med (Berl) 80: 147-162.

13. Giedraitis V, He B, Huang WX, Hillert J (2001) Cloning and mutation analysis of the human IL-18 promoter: a possible role of polymorphisms in expression regulation. J Neuroimmunol 112: 146-152.

14. Cheong JY, Cho SW, Hwang IL, Yoon SK, Lee JH, et al. (2006) Association between chronic hepatitis $B$ virus infection and interleukin-10, tumor necrosis factor- $\alpha$ gene promoter polymorphisms. J Gastroenterol Hepatol 21: 1173-1179.

15. Singh R, Kaul R, Kaul A, Khan K (2007) A comparative review of HLA associations with hepatitis $B$ and $C$ viral infections across global populations. World J Gastroenterol 13: 1770-1787.

16. Gao QJ, Liu DW, Zhang SY, Jia M, Wang LM, et al. (2009) Polymorphisms of some cytokines and chronic hepatitis B and C virus infection. World J Gastroenterol 15: 5610- 5619.

17. Macedo LC, Isolani AP, Visentainer JEL, Moliterno RA (2010) Association of cytokine genetic polymorphisms with the humoral immune response to recombinant vaccine against HBV in infants. J Med Virol 82: 929-933.

18. Zhang TC, Zhang WF, Zhao YQ, Pan FM, Gao YF, et al. (2014) Gene variation in IL10 and susceptibility to chronic hepatitis B. J Infect 69: 75-80.

19. Tunçbilek $S$ (2014) Relationship between cytokine gene polymorphisms and chronic hepatitis B virus infection. World J Gastroenterol 20: 6226-6235.

20. Zhang PA, Wu JM, Li Y (2005) Association of polymorphisms of interleukin-18 gene promoter region with chronic hepatitis $B$ in Chinese Han population. World J Gastroenterol 11: 1594-1598.

21. Sarin SK, Kumar M, Lau GK, Abbas Z, Chan HLY, et al. (2016) Asian-Pacific clinical practice guidelines on the management of hepatitis B: A 2015 update. Hepatol Int 10: 1-98.

22. Migita K, Sawakami-Kobayashi K, Maeda Y, Nakao K, Kondoh S, et al. (2009) Interleukin-18 promoter polymorphisms and the disease progression of Hepatitis B virus-related liver disease. Transl Res 153: 91-96.

23. Hirankarn N, Manonom C, Tangkijvanich P, Poovorawan Y (2007) Association of interleukin 18 gene polymorphism (-607A/A genotype) with susceptibility to chronic hepatitis B virus infection. HLA 70: 160-163.

24. Koziel MJ (1999) Cytokines in viral hepatitis. Semin Liver Dis 19: 157-169.

25. Penna A, Del Prete Gianfranco, Cavalli A, Bertoletti A, D'Elios MM, et al. (1997) Predominant T-helper 1 cytokine profile of hepatitis $B$ virus nucleocapsidspecific T cells in acute self-limited hepatitis B. Hepatology 25: 1022-1027.

26. Nayersina R, Fowler P, Guilhot S, Missale G, Cerny A, et al. (1993) HLA A2 restricted cytotoxic $T$ lymphocyte responses to multiple hepatitis $B$ surface antigen epitopes during hepatitis B virus infection. J Immunol 150: 4659-4671.

27. Bertoletti A, D'Elios MM, Boni C, De Carli Marco, Zignego AL, et al. (1997) Different cytokine profiles of intraphepatic $T$ cells in chronic hepatitis $B$ and hepatitis C virus infections. Gastroenterology 112: 193-199.

28. Sun QL, Ran W (2004) Review of cytokine profiles in patients with hepatitis World World J Gastroenterol 10: 1709-1715.

29. Vierling JM (2007) The immunology of hepatitis B. Clin Liver Dis 1: 727-759.

30. Thursz M, Yee L, Khakoo S (2011) Understanding the host genetics of chronic hepatitis B and C. In Semin Liver Dis 31: 115-127.

31. Ansari MA, Pedergnana V, LC Ip C, Magri A, Von Delft A, et al. (2017) Genometo-genome analysis highlights the effect of the human innate and adaptive immune systems on the hepatitis $C$ virus. Nat Genet 49: 666-673.

32. Lin TM, Chen CJ, Wu MM, Yang CS, Chen JS, et al. (1988) Hepatitis B virus markers in Chinese twins. Anticancer Res 9: 737-741. 
Citation: Hasan FT, Naif HM (2017) Association of Gene Polymorphisms and Serum Levels of IL-18 with the Susceptibility to Infection with Hepatitis B Virus. J Infect Dis Med 2: 117. doi: 10.4172/2576-1420.1000117

Page 7 of 7

33. Bortolotti F, Cadrobbi P, Crivellaro C, Guido M, Rugge M, et al. (1990) Longterm outcome of chronic type $B$ hepatitis in patients who acquire hepatitis $B$ virus infection in childhood. Gastroenterology 99: 805-810.

34. He D, Li M, Guo S, Zhu P, Huang H, et al. (2013) Expression pattern of serum cytokines in hepatitis $B$ virus infected patients with persistently normal alanine aminotransferase levels. J Clin Immunol 33: 1240-1249.
35. Orozco A, Gemmell E, Bickel M, Seymour GJ (2007) Interleukin 18 and periodontal disease. J Dent Res 86: 586-593.

36. Wang FS (2003) Current status and prospects of studies on human genetic alleles associated with hepatitis B virus infection. World J Gastroenterol 9: 641-644. 